\title{
Communication and Conflict in Sino-German Global Virtual Teams
}

\begin{abstract}
This study investigated the correlation between communication and conflict in Sino-German Global Virtual Teams (GVT). An exploratory quantitative online survey was conducted in German companies doing business in Greater China. A focus was given to the analysis of modern web 2.0 communication technologies and their potential influence on conflict. As expected, GVT experience more cross-cultural conflicts than collocated teams. However, there was no statistically significant difference in the amount of conflict between GVT 1.0 and GVT 2.0. Surprisingly, video calls are likely to contribute to the amount of task conflicts and cross-cultural conflicts. Furthermore, social media is likely to mitigate the amount of cross-cultural conflicts. Participants who extensively used social media and video call communication in their private lives, did so in their corporate lives as well. Finally, the team leaders who possessed a higher level of education reported a statistically higher amount of video call usage in their teams.
\end{abstract}

\section{Introduction}

Globalisation has stopped being a buzzword for more than a decade now. Historically, globalisation enabled companies in post-colonial time to build global empires. During the second half of the 20th century, multinational companies expanded their businesses to more than a hundred countries. The increasing access to personal computers revolutionised the world once more during the 1980s. It became possible to bridge time zones and national boundaries by using relatively cheap communication technologies (CT) like E-Mail.

In the 1990s it was large multinational enterprises that predominantly used modern CT like instant messaging or video conferencing. At the turn of the millennium, literature described the barriers and problems, large companies face when communicating over long distances [31]. The IT revolution directly continued as what we today call digitalisation. This buzzword describes many facets of the IT revolution which entered the web 2.0 level a few years ago [11]. Through social media websites, the user became the producer; a role which, until then, had been exclusively reserved for programmers. Google's Director of Engineering Ray Kurzweil describes this change process as exponential [4]. He believes that it is difficult to understand this process because human brains think linearly [4].

In today's virtual work environment, modern CT have already been established. What was considered exotic ten years ago is considered common practice today, e.g., work-related instant messaging, social media communication, groupware and video calls. The research problem this study deals with is how these four modern CT-we call them web 2.0 CTinfluence conflicts in Sino-German global virtual teams (GVT). The newest among them is social media communication. What started with Myspace in 2003 was the social exchange for personal matters. Today, there are many business-related social media platforms like LinkedIn, Xing or mixed platforms like Facebook and WeChat. If we look closer at such platforms, we will realise that the technologies behind these platforms are not new at all. The actual novelty is the way communication is conducted on such platforms. That means that not only has technology changed, we have changed how we use technology to communicate with each other. Our aim is to investigate how this change in communication affects our daily life in the virtual work environment. In particular, we want to investigate how web 2.0 CT might be correlated to the amount of conflicts in Sino-German GVT.

\section{Literature review and hypothesis development}

The topic of virtual teams (VT) and GVT research has been a fast-growing research area. The three most relevant literature reviews covered approximately 200 sources [35][36][40]. In a recent comprehensive literature review, it was stressed that competing terms for GVT and VT are used interchangeably [35]. In order to avoid such confusion in this paper, we followed the suggestion of literature for both terms [35]. Virtual teams are "groups of geographically, organizationally and/or time dispersed workers brought together by information and telecommunication technologies to accomplish one or more organizational tasks" [33]. A GVT is "an interdependent virtual team whose members are 
geographically and time-dispersed across cultural and national boundaries." [35].

According to literature, the term conflict was divided into two subgroups: task conflict and relationship conflict [32]. Task conflicts are conflicts between two or more people which are caused by non-interpersonal issues [32]; often disagreement in regard to the approach towards an objective. In contrast, relationship conflicts "involve problems with the relationship and the inability to resolve them" [32].

An exploratory case study discovered that Cultural Diversity might affect the amount of conflicts [18]. The study also suggested that a large amount of electronic communication can increase the amount of task conflict. These findings have been backed up by other researchers [36] who confirm that Cultural Diversity can have a negative effect on communication. In this study we want to address all three grounds as well: culture, conflict and communication.

Culture and cultural differences are one of the most critical areas in GVT which research needs to address [31]. Many large research projects have dealt with the question of what culture really is, how it can be differentiated and how it can be measured. The Hofstede model, a four-dimensional cultural model emerged which undergraduates learn in universities all around the world [15]. This model is the result of one of the largest surveys ever conducted about cultural dimensions. It originally categorised a large amount of relevant cultures into four dimensions: power distance, uncertainty avoidance, masculinity vs. femininity and individualism vs. collectivism. Each culture considered in the study received a certain score for each of the four dimensions. One major drawback of that study is that it was conducted almost 40 years ago. Thanks to globalization, the world has undergone a significant transformation.

Another problem with this model is that the data were collected among private individuals and not businesses. For instance, the Hofstede model argues that the Chinese are long-term oriented. In contrast to that statement, other researchers found out that this is not true for the business context. In business, Chinese seem shorter term oriented than many Western European cultures [24].

Alternative models have emerged and the rather simple Hofstede model encounters more sophisticated models like the Cultural Mosaic model [5]. The Cultural Mosaic model attempts to describe an individual's culture as the collective picture of many small mosaics, e.g. nationality or demographics. Despite its weaknesses, the Hofstede model is probably still the most commonly used cultural model and models like this enable us to understand the complexity of culture and cultural differences. This understanding helps us to grasp complex phenomena like cross-cultural conflicts.

In some Western societies, people might think that conflict per se is not a bad thing and that there can be positive conflicts. Some researchers argue that conflict can even increase creativity [21]. This might be true in closed homogenous ecosystems. We do not believe that this is true for cross-cultural conflicts, especially in environments where Western and Eastern cultures are mixed. German companies doing business in or with China are operating in such heterogenous environments. Avoiding conflict is one of the top priorities of many Chinese managers. Another study found that Chinese have a very different approach to work and private relationships compared to Germans ]23]. In China professional and private relationships are more interconnected than in Germany. Respondents of a study reported that harmony at work makes employees more satisfied with their job [3].

Literature provides an increasingly high number of references on the topic of cross-cultural conflicts. A quantitative study developed a tool called "The Intercultural Conflict Style Inventory" which aims at the resolution of cross-cultural conflicts [12]. In case of a cross-cultural conflict, the user is supposed to use Hammer's theoretical framework to solve the conflict. The study shows a very robust methodology, including a large survey and a thoroughly conducted factor analysis. In addition to this study, a vast overview and industry examples of cross-cultural communication combined with guidelines on how to manage cross-cultural differences were provided by another research team [29].

In order to make cross-cultural conflicts comprehensible, we developed a technique to measure cross-cultural conflicts. It was claimed that cross-cultural conflicts can happen because of Language Difficulties or Cultural Diversity [15]. Cross-cultural conflicts caused by Language Difficulties often occur when two parties do not speak the same native language. This lack of common ground leads to misunderstandings which then lead to conflict. Cross-cultural conflicts due to Cultural Diversity are different. The cultural background of one party creates expectations towards another party which are not met because the other party does not know about these expectations or for any other reason does not want to meet these expectations. A conflict is the consequence of these unfulfilled expectations due to Cultural Diversity. We combined this idea with an existing categorisation of conflict [32]. In our definition, a 
cross-cultural conflict can be a task or relationship conflict caused by Language Difficulties or Cultural Diversity. Thus, cross-cultural conflicts are not a third type of conflict but task and relationship conflicts with specific antecedents that only occur in cross-cultural setups.

There is some evidence to suggest that too much communication could lead to an increasing amount of conflicts and even to cognitive overload - a status where the user cannot process any more information [38]. This stance is backed by more recent findings [18]. However, this theory does not fully explain what role web 2.0 CT play.

Another camp in literature argues that modern CT can decrease the amount of conflict in virtual teams. This argumentation has mainly to do with a CT's latency (immediateness of feedback). In this study, we did not measure latency per se but the different CT do have different levels of latency. A broad categorisation can be achieved by dividing CT into asynchronous and synchronous CT. In this definition, synchronous CT expect a direct response and asynchronous CT do not. Asynchronous communication methods might decrease the negative perception of aggressive emotions because no direct response is needed [28]. This would imply that aggressive emotions communicated via telephone (synchronous) have a more negative perception than the same emotions expressed via E-Mail (asynchronous). This study has two shortcomings. Firstly, other studies found that trust building is more difficult for written than for spoken communication [16]. Secondly, Montoya-Weiss, Massey and Song (2001) did not anticipate that hybrid CT would emerge [28]. Sending text messages is considered asynchronous. However, the sender of an instant message on a mobile device usually expects a quicker response than an E-Mail sender. This means that the latency for two different types of asynchronous CT can be very different and therefore it seems difficult to derive a general meaning from this classification. Therefore, we did not follow the classification of asynchronous and synchronous CT for hypothesis testing (but we did consider it for the interpretation of results). Instead, we followed the categorisation of web 2.0 and traditional CT for which we developed the Communication Technology Index (CTI) in a previous study [17].

The collaboration technology readiness list provides suggestions about what CT might be adopted in what order [31]. Team members in GVT usually do not have a say regarding media adoption. This path is usually already set by the organisation in which they work. The question is not whether to use asynchronous or synchronous CT, the question is how far teams have advanced on their journey to the certain adoption of web $2.0 \mathrm{CT}$, regardless of the CT's latency. Applying the CTI divides all GVT into two groups which can be compared to each other with regard to the amount of task and relationship conflict (Hypothesis 1). The first group comprises teams that rely heavily on the usage of web $2.0 \mathrm{CT}$, we call them GVT 2.0. The second group still relies mainly on traditional CT, we call them GVT 1.0. Although we assumed that GVT 2.0 experienced less conflict than GVT 1.0 we did not have sufficient evidence to form a directional hypothesis.

The CTI measures the frequency of usage of the most commonly used CT. Among them are four CT which we call web $2.0 \mathrm{CT}$ : social media, instant messaging, video calls and groupware communication. In order to get a deeper understanding of how the individual CT might affect conflict, they will be tested for their correlation with different conflict types (Hypothesis 2).

The third hypothesis compares the amount of conflict between collocated teams and GVT. The majority of references on the topic posit that GVT experience more conflict than collocated teams; for a plethora of different reasons, e.g., geographical distance (Olson and Olson, 2000). There is reason to believe that this is an outdated stance which does not hold true anymore. Web 2.0 CT might positively mediate communication effectiveness within GVT. Furthermore, modern teams might be increasingly used to working in multicultural setups. This experience could have also led to a better understanding of other cultures. It might be the case that because of these reasons, GVT do not experience a higher amount of conflicts than collocated teams anymore. This is tested in Hypothesis 3. As there is no consensus in literature about the amount of conflict in virtual teams, no directional hypothesis was formed.

A recent study showed that personal preference represents a driving factor when team members introduce social media communication [1]. Hypothesis 4 tests whether this finding holds for other web 2.0 CT in Sino-German GVT as well. We also believe that the team leader plays a vital role regarding collaboration technology readiness. He might not only be an influencer but in some caseshe might be the dictator of which CT should be used.

Hypothesis 5 was not included in the literature review as the finding was a coincidental result of this study. We assumed that a higher education of the team leader leads to a quicker adoption of web 2.0 $\mathrm{CT}$ and consequently to a more frequent use of web $2.0 \mathrm{CT}$ than the control group. 
The hypotheses which were developed are presented as follows:

H1: The amount of conflict is different in SinoGerman GVT 2.0 compared to GVT 1.0.

H2: The usage of individual web 2.0 CT correlates with the amount of conflict.

H3: The amount of conflict is different in collocated teams compared to GVT.

H4: A frequent personal usage of web $2.0 \mathrm{CT}$ correlates with a higher usage of these technologies in the team environment.

H5: A higher education level of the team leader correlates with a more frequent use of web 2.0 CT within the team.

This section has demonstrated that a thorough review of literature has been conducted which led to the establishment of a framework of variables and concise and testable hypotheses. A quantitative survey seemed to be the ideal data collection method as it could cover a large amount of GVT and collect all the necessary information about the team characteristics, the participant's demographics, the usage behavior of CT and the amount of conflict.

\section{Methodology}

An online survey was the basis of our study's research design and a cost-effective [6] method to collect up to date empirical data from a relevant business context [34] as successfully demonstrated by other GVT studies [12][30].

The questionnaire which we developed for this online survey consists of two parts. The first part asks questions about the individual participant. The second part asks questions about the participant's team (see table 1 and 2).

The online survey was set up using GoogleForms [25]. It was not mandatory for participants to type in data in response to one question in order to proceed to the next question.

\subsection{Reliability and validity checks}

In statistical terms, reliability can be described as "the extent to which items in a scale are intercorrelated, thus measuring the same construct" [39]. The reliability of the questionnaire has been checked by calculating the internal consistency reliability using IBM's SPSS 22. The cases 18, 72, 73, 75 and 79 were excluded listwise from the reliability calculation as they did not enter all of the questionnaire items for one research construct. The threshold for excluding cases from analysis was one or more missing answers for one research construct.
Although being excluded from the reliability check, some of these cases could still be used for further data analysis. All scales used for measuring the research constructs task conflict, relationship conflict and cross-cultural conflicts were ordinal scales. The results of this internal consistency calculation can be found in the results section. Validity was assured by three techniques: attention filters, content validity and the implementation of reverse wording [39].

\subsection{Sampling design}

An adequate sample size is the most important factor for the validity of data analysis [10]. G*Power 3 was used to calculate the minimum sample size required $(n=54)$ [9]. We added a $15 \%$ security margin for invalid responses and estimated a $10 \%$ response rate which led to 620 companies to be contacted. A random sampling process was conducted on a probability basis using Excel's RAND function to reduce bias which could influence the selection of individual companies from the database.

\subsection{Data collection procedure}

The company database of the German Chamber of Commerce provided names of companies, locations of headquarters and in many cases, also the homepage of the company.

The telephone calls started in November 2016 and terminated in August 2017.

After having collected the data, we conducted reliability and validity checks to ensure a high-quality data set. Hypothesis testing was conducted using Mann-Whitney U and Somers' D statistics.

Initially, a 20 EUR voucher for an online shop was used as an incentive. Later, this incentive was changed to a 10 EUR charity donation in order to increase the response rate.

\section{Results and data analysis}

\subsection{Participants}

Of the study population, 82 subjects completed and returned the questionnaire. Eleven respondents failed the validity check's attention filter at question 12 (case 5, 17, 22, 27, 28, 44, 48, 53, 71, 77, 78). Consequently, they were excluded from the survey and the remaining 71 cases were used for data analysis. 


\begin{tabular}{|c|c|c|c|c|c|}
\hline Research Construct & Item no. & Question Type & Scale of Measurement & Type of Data & Resource \\
\hline Nationality & 1 & Demographics & Multiple choice & Nominal data & $\begin{array}{l}\text { (Hofstede, } \\
\text { Hofstede and } \\
\text { Minkov, 2010) }\end{array}$ \\
\hline $\begin{array}{l}\text { Feeling of } \\
\text { belongingness to a } \\
\text { cultural group }\end{array}$ & 2 & Demographics & Multiple choice & Nominal data & Self-developed \\
\hline Gender & 3 & Demographics & Multiple choice & Nominal data & Self-developed \\
\hline Educational level & 4 & Demographics & Multiple choice & Nominal data & $\begin{array}{l}\text { (Hammer, } \\
2005)\end{array}$ \\
\hline Age & 5 & Demographics & Multiple choice & Ordinal data & $\begin{array}{l}\text { (Hammer, } \\
2005)\end{array}$ \\
\hline $\begin{array}{l}\text { World region brought } \\
\text { up in }\end{array}$ & 6 & General culture & Multiple choice & Nominal data & $\begin{array}{l}\text { (Hammer, } \\
2005)\end{array}$ \\
\hline $\begin{array}{l}\text { Time spent in another } \\
\text { culture }\end{array}$ & 7 & General culture & Multiple choice & Ordinal data & $\begin{array}{l}\text { (Hammer, } \\
2005)\end{array}$ \\
\hline Position in team & 8 & Team & Multiple choice & Nominal data & Self-developed \\
\hline $\begin{array}{l}\text { Individual usage of } \\
\text { web } 2.0 \\
\text { communication } \\
\text { technologies }\end{array}$ & $9-11$ & $\begin{array}{l}\text { Individual } \\
\text { communication }\end{array}$ & Multiple choice & Ordinal data & Self-developed \\
\hline Validity check & 12 & Validity check & Multiple choice & Nominal data & Self-developed \\
\hline
\end{tabular}

\begin{tabular}{|c|c|c|c|c|c|}
\hline Research Construct & Item no. & Question Type & $\begin{array}{l}\text { Scale of } \\
\text { Measurement }\end{array}$ & Type of Data & Resource \\
\hline Team size & 13 & Team & Multiple choice & Ordinal data & Self-developed \\
\hline Type of work & 14 & Team & Multiple choice & Nominal data & Self-developed \\
\hline Sino-German Team & 15 & Team & Multiple choice & Nominal data & Self-developed \\
\hline Virtual Team & 16 & Team & Multiple choice & Nominal data & Self-developed \\
\hline $\begin{array}{l}\text { Task / Relationship } \\
\text { conflict }\end{array}$ & $17-28$ & Conflict type & Multiple choice & Ordinal data & $\begin{array}{l}\text { (Miranda and } \\
\text { Bostrom, } 1993 \\
\text { cited in } \\
\text { Kankanhalli, Tan } \\
\text { and Wei, 2007) }\end{array}$ \\
\hline $\begin{array}{l}\text { Cross-cultural } \\
\text { conflict; language or } \\
\text { culture based }\end{array}$ & $29-34$ & $\begin{array}{l}\text { Cross-cultural } \\
\text { conflict }\end{array}$ & Multiple choice & Ordinal data & Self-developed \\
\hline $\begin{array}{l}\text { Team usage of web } \\
2.0 \text { communication } \\
\text { technologies }\end{array}$ & $35-42$ & $\begin{array}{l}\text { Team } \\
\text { communication }\end{array}$ & Multiple choice & Ordinal data & Self-developed \\
\hline $\begin{array}{l}\text { Participant may } \\
\text { choose charity for } \\
\text { the donation } \\
\text { (incentive) }\end{array}$ & 43 & $\begin{array}{l}\text { Incentive / } \\
\text { Donation }\end{array}$ & Multiple choice & Nominal data & Self-developed \\
\hline
\end{tabular}




\subsection{Reliability calculation}

Reliability checks were conducted for the four research constructs: task conflict, relationship conflict, cross-cultural conflict caused by Language Difficulties and cross-cultural conflicts caused by Cultural Diversity.

The internal consistency was calculated by using the Coefficient Alpha (also known as Cronbach's alpha). Generally speaking, the higher the Coefficient Alpha, the better. It is argued that a robust value of internal consistency should be 0.7 or higher [7]. The Pearson correlation coefficients for each item should be higher than 0.3 as recommended by literature [20].

The construct "task conflict" consisted of six questions. A total of two cases were excluded by the statistic. The scale showed a high level of internal consistency, as determined by a Coefficient Alpha of 0.75. The items were measuring the same construct, as indicated by the Pearson correlation coefficients between $0.36-0.70$ for all items.

The construct "relationship conflict" consisted of 6 questions. A total number of four cases were excluded by the statistic. The scale showed a high level of internal consistency, as determined by a Coefficient Alpha of 0.74. The items were measuring the same construct, as indicated by the Pearson correlation coefficients between 0.28 and 0.59 for all items. Only one item was slightly below the 0.3 threshold recommended by literature (item 18;0.28).

The construct "cross-cultural conflict caused by language difficulties" consisted of 3 questions. A total of 2 cases were excluded by the statistic. The scale showed a high level of internal consistency, as determined by a Coefficient Alpha of 0.85. The items were measuring the same construct, as indicated by the Pearson correlation coefficients of $0.67,0.80$ and 0.82 .

The construct "cross-cultural conflict caused by cultural differences" consisted of 3 questions. A total of 2 cases were excluded by the statistic. The scale showed a high level of internal consistency, as determined by a Coefficient Alpha of 0.91. The items were measuring the same construct, as indicated by the Pearson correlation coefficients of $0.79,0.88$ and 0.81 . In the next section, the principal results of data analysis will be presented.

\subsection{Hypothesis testing}

4.2.1. Hypothesis 1 Several between-group mean comparisons were conducted on the different kinds of conflicts. Neither type of conflict showed a statistically significant different amount in the two groups GVT 1.0 and 2.0.

4.2.2. Hypothesis 2 Somers' $D$ was run to determine the association between the usage of a communication technology and the amount of specific types of conflict.

There was a strong, positive correlation between the frequency of video calls used as a communication technology and the amount of task conflict, which was statistically significant $(\mathrm{n}=65, \mathrm{~d}=.284, \mathrm{p}<$ 0.001).

There was a strong, positive correlation between the frequency of video calls used as a communication technology and the amount of cross-cultural conflicts because of Cultural Diversity, which was statistically significant $(\mathrm{n}=65, \mathrm{~d}=.208, \mathrm{p}<0.008)$.

There was a strong, negative correlation between the frequency of social media applications being used as a communication technology and the amount of cross-cultural conflicts because of Cultural Diversity, which was statistically significant $(n=66, d=-.168$, $\mathrm{p}<0.035)$.

4.2.3. Hypothesis 3 Distributions of the amount of cross-cultural conflicts caused by Language Difficulties for GVT and collocated teams were similar, as assessed by visual inspection. The amount of cross-cultural conflicts caused by Language Difficulties was statistically significantly different between GVT $(n=40$, mean rank= 35.6, $\mathrm{Mdn}=1$ ) and collocated teams $(\mathrm{n}=22$, mean rank $=24.05$, $\mathrm{Mdn}=1), \mathrm{U}=604, \mathrm{z}=2.828, \mathrm{p}=0.005$, using an exact sampling distribution for $\mathrm{U}[8]$.

Distributions of the amount of cross-cultural conflicts caused by Cultural Diversity for GVT and collocated teams were similar, as assessed by visual inspection. The amount of cross-cultural conflicts caused by Cultural Diversity was statistically significantly different between virtual GVT ( $n=40$, mean rank=37,29, Mdn =2) and collocated teams ( $\mathrm{n}$ $=22$, mean $\operatorname{rank}=20,98, \operatorname{Mdn}=1), \mathrm{U}=671, \mathrm{z}=$ $3.681, \mathrm{p}=0.005$, using an exact sampling distribution for $\mathrm{U}[8]$.

4.2.4. Hypothesis 4 There was a strong, positive correlation between the amount of usage of social media applications used for private purposes and the amount of usage of social media applications used at work, which was statistically significant $(\mathrm{n}=71, \mathrm{~d}=$ $.401, \mathrm{p}<0.0005)$.

Another strong, positive correlation was measured between the frequency of video calls used for private purposes and the amount video calls used at work. This correlation was statistically significant $(n=71$, 


\begin{tabular}{|c|c|c|c|c|}
\hline Hypothesis & Statistic & $\begin{array}{l}\text { Cases } \\
\text { (n) }\end{array}$ & Test results & $\begin{array}{l}\text { Hypothesis } \\
\text { supported }\end{array}$ \\
\hline 1 & $\begin{array}{l}\text { Mann- } \\
\text { Whitney U }\end{array}$ & 41 & $\begin{array}{l}U=183, z=-0,701, p= \\
0,483 \text { for relationship } \\
\text { conflicts } \\
U=236, z=0,763, p=0,445 \\
\text { for task conflicts }\end{array}$ & Not supported \\
\hline $\begin{array}{l}2 \\
\text { call) }\end{array}$ (video & Somers' D & 65 & $\begin{array}{l}\mathrm{d}=.284, \mathrm{p}<0.001 \text { for task } \\
\text { conflicts } \\
\mathrm{d}=.208, \mathrm{p}<0.008 \text { for cross- } \\
\text { cultural conflicts because of } \\
\text { Cultural Diversity }\end{array}$ & supported \\
\hline $\begin{array}{l}2 \text { (social } \\
\text { media) }\end{array}$ & Somers' D & 66 & $\begin{array}{l}\mathrm{d}=-.168, p<0.035 \text { for } \\
\text { cross-cultural } \quad \text { conflicts } \\
\text { because of Cultural Diversity }\end{array}$ & supported \\
\hline $\begin{array}{l}3 \\
\text { (Language } \\
\text { Difficulties) }\end{array}$ & $\begin{array}{l}\text { Mann- } \\
\text { Whitney U }\end{array}$ & 62 & $\mathrm{U}=604, \mathrm{z}=2.828, \mathrm{p}=0.005$ & supported \\
\hline $\begin{array}{l}3 \text { (Cultural } \\
\text { Diversity) }\end{array}$ & $\begin{array}{l}\text { Mann- } \\
\text { Whitney U }\end{array}$ & 62 & $\mathrm{U}=671, \mathrm{z}=3.681, \mathrm{p}=0.005$ & supported \\
\hline 4 & Somers' D & 71 & $\begin{array}{l}d=401, p<0.0005 \text { for } \\
\text { social media } \\
d=.483, p<0.0005 \text { for video } \\
\text { call }\end{array}$ & supported \\
\hline 5 & Somers ${ }^{i} \mathrm{D}$ & 35 & $\begin{array}{l}\mathrm{d}=.293, \mathrm{p}<0.056 \text { for video } \\
\text { calls }\end{array}$ & supported \\
\hline
\end{tabular}

$\mathrm{d}=.483, \mathrm{p}<0.0005)$

4.2.5. Hypothesis 5 There was a strong, positive correlation between the education level of the team leader and the amount of usage of video calls used at work, which was statistically significant $(\mathrm{n}=35, \mathrm{~d}=$ $.293, \mathrm{p}<0.056)$.

\section{Discussion and Conclusion}

This research expands GVT literature as it concentrates on culture as one of the most important factors [31]. To our knowledge it is the first quantitative research project about conflict and communication in Sino-German GVT.

It was identified that a difference in the amount of conflict between GVT 1.0 and GVT 2.0 is not likely (H1) as there was no statistically significant difference measured. However, the results of the statistics in regard to $\mathrm{H} 2$ showed that teams who used a high amount of video call communication experienced more task conflicts and cross-cultural conflicts than the control group. In contrast, teams who used a high amount of social media communication experienced a lower amount of crosscultural conflicts. A higher amount of cross-cultural conflicts was measured in GVT compared to collocated teams. Social media and video calls were used more often in the work environment when the participant also frequently used these CT for private purposes. Finally, team leaders with a high educational background relied on video calls for communication more often.

Unexpectedly, groups that belong to the web 2.0 category did not show a different amount of conflict than the web 1.0 group (H1). Synchronous communication technologies like video calls are rich media which we thought might help to get misunderstandings solved quickly. This stance was backed up by literature [18].

As video call communication positively and social media communication negatively correlate with the amount of conflict, both communication technologies seem to even each other out in regard to the conflict amount. We then asked ourselves why social media communication would correlate with a lower amount of conflict and why video call communication would correlate with a higher amount of conflict in GVT. This is a totally new phenomenon which has not yet been investigated in this context. The novelty of this contribution makes a direct comparison to existing references difficult. Furthermore, social media communication is a very broad umbrella term covering a large variety of different software applications. In our online survey, we provided examples of CT to make sure that the participants understand what is meant by, e.g. social media. Most of the social media apps on the market seem to have in common that communication is usually conducted asynchronously. This could be one of the reasons why social media communication, in contrast to video call communication, correlates with a lower amount of cross-cultural conflicts in SinoGerman GVT. Video calls are considered synchronous communication and social media apps are considered asynchronous. Asynchronous communication gives the sender of information enough time to think about what to write or look up information or translate a text in case Language Difficulties exist. Using asynchronous communication methods also gives the responder more time to gather relevant information and to clear up misconceptions as an immediate response is not expected.

However, this explanation would totally be in contrast to other researchers [18] who argue that it is synchronous communication which leads to less conflict. These researchers followed a qualitative study in a university environment not an industry context. Additionally, our study was conducted in German companies operating in Greater China, whereas the comparison study was conducted in a 
heterogenous setting consisting of students in Singapore [18]. The time period during which teams in business contexts exist is usually long-term compared to short-term student teams. However, it could still be possible that both studies' findings hold in their particular environment.

Social media communication is not only less intrusive than e.g., an unexpected phone or video call but it is usually also less formal and often spontaneous. This explanation is in good agreement with other researchers [14] who posit that informal and spontaneous communication like social media might decrease the amount of conflict in virtual teams for task and relationship conflicts. We believe that this is likely to be true for social media communication in Sino-German GVT.

Surprisingly, video call communication correlated with a higher amount of conflict. This is unexpected because it should provide a rich exchange of information and it should help to decrease potential misunderstandings due to additional means of communications which are absent at other CT, e.g., facial expressions and gestures. Also, video communication is supposed to increase trust in GVT. A higher amount of trust should lead to less conflict and not to more conflict. It is likely that the SinoGerman cross-cultural setup is a fruitful environment for such types of conflict. Without the cross-cultural context of Language Difficulties and Cultural Diversity, video call communication might not have any effect on the amount of task conflict in GVT. It would be interesting to see the results of a similar study conducted in homogenous teams. If those teams do not show a statistically significant amount of task conflict between video call users and the control group our anticipation is likely to be valid.

In contrast to teams that rely heavily on social media or video call communication, teams that used a high amount of groupware communication or instantmessaging did not show a statistically significantly different amount of conflict. Regarding instantmessaging this is likely because of the extensive usage of instant-messaging in most teams of the industry. The majority of teams already use this CT daily, so that there are hardly any non-users left. Groupware communication did not show a correlation to the amount of conflict either. As an asynchronous CT it is not likely to trigger conflict in Sino-German GVT easily because there is no direct spoken communication between a potential direct German and a potential indirect Chinese team member. Also, most groupware tools deal with processes of tasks and project and less with the communication between people. Groupware is not likely to mitigate conflict in Sino-German GVT either because it lacks elements that enhance positive variables such as trust-building, informality or spontaneity.

Working remotely across borders still seems to provide a basis for conflict. As the results of $\mathrm{H} 3$ show, modern CT do not seem to be able to bridge the distance gap completely as GVT experience a higher amount of conflict than collocated teams. This finding is consistent with other researchers [18][31] who claimed that virtual work provides more ground for conflict than collocated working. In literature, there are various reasons that make an attempt to explain that difference. Among them are Cultural Diversity, geographical distribution, different time zones, language barriers or communication technologies [13][14][31][35]. It is interesting to see that in our study both cross-cultural conflict antecedents (Language Difficulties and Cultural Diversity) showed statistically significantly results. Of course, GVT are usually more heterogenous than collocated teams and therefore they have more potential for both types of antecedents. This knowledge is particular interesting when it is put into relation with the results of $\mathrm{H} 2$. Knowing that crosscultural conflicts happen more often in GVT, web 2.0 CT can now be used to influence those effects, e.g. using video call communication carefully and implementing social media communication to mitigate cross-cultural conflicts.

The findings about the personal usage of modern web 2.0 CT have not been our main research objective. These findings are nevertheless useful and interesting and complement those of earlier studies. The finding that team members who use video calls and social media in their private lives use them more frequently in a business context shows that in today's modern work environment, there is no clear line between work and private life when it comes to the usage behavior of CT. What people learn at work might be transferred to life and vice versa. This finding is in compliance with other research [1] that posits that a CT is adopted by the choice of the user.

Another more significant finding to emerge from this study is that team leaders with a high education use video call communication more often at work as well. This interesting finding was a coincidental result after several correlation tests were run between demographics and CT. It can be argued that team leaders who have a higher education and who went to university had early contact with video call communication. In most universities, there are projects throughout the courses which require the students to work in VT in order to solve tasks. This early adoption of video calls might have supported an early adoption in the GVT of the team leader. 
Another idea is that well educated team leaders are more likely to work in larger companies which use video calls more often than smaller enterprises.

However, some limitations are worth noting. The results of this study show associations and differences between groups. As no qualitative data were collected, the results might not explain causality between variables. This facilitates the risk of misinterpreting the results. A follow-up mixed method research project will address this shortcoming which might also affect the ability to draw conclusions from this study. Additionally, our study was conducted among Sino-German teams. It might be that other constellations with Western cultures, e.g., Sino-American teams show different results because the cultural dimensions of the American culture differ from the German culture [15].

This study indicates that teams that frequently use video calls to communicate over distance need to be careful about a potentially higher amount of conflict. Such teams might think about using social media applications in addition as they might decrease the amount of conflict. Most notably, this is the first study to our knowledge to investigate the effect of web 2.0 CT on various types of conflict in SinoGerman GVT. Our results provide compelling evidence on the contribution of web 2.0 CT on the amount of conflict. These findings might help team leaders of Sino-German GVT to better understand the correlation of CT and conflict and consequently reduce the amount of conflict in their teams.

Taken together, these findings suggest a role for video call communication in promoting both task conflicts and cross-cultural conflicts. This study also suggests that using social media applications in the GVT environment is likely to decrease the amount of cross-cultural conflicts. The amount of cross-cultural conflicts caused by both Language Difficulties and Cultural Diversity was higher in virtual than in collocated teams. Practitioners in the field should be aware of these correlations as they might affect the performance within their teams.

\section{References}

[1] Anders, A. "Team communication platforms and emergent social collaboration practices." International Journal of Business Communication, 53 (2016), 224-261.

[2] Ang, S., Van Dyne, L. and Koh, C. "Personality correlates of the four-factor model of cultural intelligence." Group \& Organization Management, 31 (2006), 100-123.
[3] Burke, R. J., Astakhova, M. N. and Hang, H. "Work passion through the lens of culture: Harmonious work passion, obsessive work passion, and work outcomes in Russia and China." Journal of Business and Psychology, 30 (2015), 457-471.

[4] Cadwalladr, C. "Are the robots about to rise? Google's new director of engineering thinks so..." [Online]. Available: https://www.theguardian.com/tech-nology/2014/ feb/22/robots-google-ray-kurzweil-terminator-singularityartificial-intelligence [Accessed October 31, 2017].

[5] Chao, G. T. and Moon, H. "The cultural mosaic: a metatheory for understanding the complexity of culture." Journal of Applied Psychology, 90 (2005), 1128-1140.

[6] Cobanoglu, C., Warde, B. and Moreo, P. J. "A comparison of mail, fax and web-based survey methods." International journal of market research, 43 (2001), 441452.

[7] Devellis, R. F., Scale development: Theory and applications, Sage Publications, Thousand Oaks, 2016.

[8] Dinneen, L. and Blakesley, B.. "Algorithm AS 62: a generator for the sampling distribution of the MannWhitney U statistic". Journal of the Royal Statistical Society. Series C (Applied Statistics), 22 (1973), 269-273.

[9] Faul, F., Erdfelder, E., Lang, A.-G. and Buchner, A. "G* Power 3: A flexible statistical power analysis program for the social, behavioral, and biomedical sciences." Behavior research methods, 39 (2007), 175-191.

[10] Field, A. Discovering Statistics using IBM SPSS Statistics, Sage Publications, London, 2013.

[11] Fuchs, C., Boersma, K., Albrechtslund, A. and Sandoval, M., "Internet and Surveillance: The Challenges of Web 2.0 and Social Media." American Sociological Association, 2012.

[12] Hammer, M. R. "The Intercultural Conflict Style Inventory: A conceptual framework and measure of intercultural conflict resolution approaches." International Journal of Intercultural Relations, 29 (2005), 675-695.

[13] Hinds, P. J. and Bailey, D. E. "Out of sight, out of sync: Understanding conflict in distributed teams." Organization science, 14 (2003), 615-632.

[14] Hinds, P. J. and Mortensen, M. "Understanding conflict in geographically distributed teams: The moderating effects of shared identity, shared context, and spontaneous communication." Organization science, 16 (2005), 290-307.

[15] Hofstede, G., Hofstede, G. J. \& Minkov, M., Cultures and Organizations, Software of the mind. Intercultural Cooperation and Its Importance for survival, McGraw-Hill, New York, 2010. 
[16] Jensen, C., Farnham, S. D., Drucker, S. M. and Kollock, P. "The effect of communication modality on cooperation in online environments." Proceedings of the SIGCHI conference on Human Factors in Computing Systems, ACM, 470-477, 2000.

[17] Jurack, A. "Developing the Communication Technology Index - a tool to measure how modern the communication in a virtual team setup really is." DBA Conference, Manchester, 2016.

[18] Kankanhalli, A., Tan, B. C. Y. and Wei, K.-K. "Conflict and Performance in Global Virtual Teams." Journal of Management Information Systems, (2007), 237274.

[19] Laerd-Statistics. Cronbach's alpha using SPSS Statistics. Statistical tutorials and software guides. [Online]. Available: https://statistics.laerd.com/ (2015a) [Accessed December 10, 2017].

[20] Laerd-Statistics. Mann-Whitney U test using SPSS Statistics [Online]. Available: Retrieved from https://statistics.laerd.com/ (2015b) [Accessed July 25, 2018].

[21] Lee, S. Conflict Is Good for Creativity [Online]. Available: https://knowledge.insead.edu/leadershiporganisations/conflict-is-good-for-creativity-4105 (2015) [Accessed June 18, 2018].

[22] Lisak, A. and Erez, M. "Leadership emergence in multicultural teams: The power of global characteristics." Journal of World Business, 50 (2015), 3-14.

[23] LU, L. "Relation From the Perspectives of Chinese Culture and German Culture: Cases Analysis of Networking in Germany-Funded Enterprises." Canadian Social Science, 12 (2016), 41-44.

[24] Lügger, K., Geiger, I., Neun, H. and Backhaus, K.. "When East meets West at the bargaining table: adaptation, behavior and outcomes in intra- and intercultural GermanChinese business negotiations." Zeitschrift für Betriebswirtschaft, 85 (2015), 15-43.

[25] Mallette, M. and Barone, D. „On using Google forms.“ The Reading Teacher, 66 (2013), 625-630.

[26] McDonough, E. F., Kahnb, K. B. and Barczaka, G.. "An investigation of the use of global, virtual, and colocated new product development teams." Journal of product innovation management, 18 (2001), 110-120.

[27] Miranda, S. M. and Bostrom, R. P. "The impact of group support systems on group conflict and conflict management." Journal of Management Information Systems, (1993) 63-95.
[28] Montoya-Weiss, M. M., Massey, A. P. and Song, M. "Getting it together: Temporal coordination and conflict management in global virtual teams." Academy of management Journal, 44 (2001), 1251-1262.

[29] Moran, R. T., Abramson, N. R. and Moran, S. V. Managing cultural differences, Routledge, London, 2014.

[30] Oetzel, J., Ting-Toomey, S., Masumoto, T., Yokochi, Y., Pan, X., Takai, J. and Wilcox, R. "Face and facework in conflict: A cross-cultural comparison of China, Germany, Japan, and the United States." Communication Monographs, 68 (2001), 235-258.

[31] Olson, G. M. and Olson, J. S. "Distance matters." Human-Computer Interaction, 15 (2000), 139-178.

[32] Pinkley, R. L. "Dimensions of conflict frame: Disputant interpretations of conflict." Journal of applied psychology, 75 (1990), 117-126.

[33] Powell, A., Piccoli, G. and Ives, B. "Virtual teams: a review of current literature and directions for future research.” ACM Sigmis Database, 35 (2004), 6-36.

[34] Rossi, P. H., Wright, J. D. and Anderson, A. B. Handbook of survey research, Elsevier, Amsterdam, 2013.

[35] Scott, C. P. and Wildman, J. L. "Culture, Communication, and Conflict: A Review of the Global Virtual Team Literature." Leading Global Teams. Springer, (2015) 13-32.

[36] Shachaf, P. "Cultural diversity and information and communication technology impacts on global virtual teams: An exploratory study." Information \& Management, 45 (2008), 131-142.

[37] Smith, C. https://docs.google.com is $100 \%$ blocked in China (2016) [Online]. Available: https://en.greatfire.org/https/docs.google.com [Accessed January 20, 2016].

[38] Spiro, R., Feltovich, P., Jacobson, M. and Coulson, R. L. "Cognitive flexibility, constructivism, and hypertext: Random access instruction for advanced knowledge acquisition in ill-structured domains." Routledge, Constructivism in education., 81 (2001), 57-75.

[39] Terwee, C. B., Bot, S. D., De Boer, M. R., Van Der Windt, D. A., Knol, D. L., Dekker, J., Bouter, L. M. and De Vet, H. C. "Quality criteria were proposed for measurement properties of health status questionnaires." Journal of clinical epidemiology, 60 (2007), 34-42.

[40] Zimmermann, A. "Interpersonal relationships in transnational, virtual teams: Towards a configurational perspective." International Journal of Management Reviews, 13 (2011), 59-78. 